\title{
DIE ONTWERP VAN 'N WERKMONSTERTOETS VIR DIE KEURING VAN SWART ELEKTRISIËNAMBAGMANHELPERS
}

\author{
J.B. WORFAARDT ${ }^{*}$ \\ DEPARTEMENT BEDRYFSIELKUNDE \\ UNIVERSITEIT VAN SUID-AFRIKA
}

\begin{abstract}
A work sample test, the Cable Joints Test, which could serve as a selection instrument for Black electrician aides in the mining industry was designed and applied with a rating scale as criterion. The predictors were scores on two testings with the work sample, an improvement score, Dudec and related job experience. A validation study $(N=53)$ yielded low reliability coefficients and no significant correlation between predictors and criterion, but a cross validation $(N=62)$ had shown that a combination of the second test score and Dudec combined could predict work performance. However, the multiple correlations $(0,40$ to 0,52$)$ were low and the variance explained inadequate to be of any practical value in a selection battery.
\end{abstract}

Die sukses wat behaal is met die gebruik van werkmonstertoetse vir die keuring van applikante vir beroepe wat veral psigomotoriese vaardighede vereis, is reeds deur Wolfaardt (1984) gemeld.

Aangesien daar geen wetenskaplike keuringinstrument beskikbaar was vir die keuring van Swart ambagsmanhelpers nie, is 'n versoek deur die mynbouindustrie aan die Laboratorium vir Menslike Hulpbronne van die Kamer van Mynwese van Suid-Afrika gerig om aandag te skenk aan die ontwikkeling van 'n keuringinstrument. Daar is versoek dat, sover moontlik, voorkeur verleen moet word aan toetse. Die aanvanklike studie is beperk tot een van die drie tipes ambagsmanhelpers in die bedryf, naamlik elektrisiën-helpers (electrician aides). Die ander twee tipes - passer-helpers (fitter aides) en ketelmakerhelpers (boilermaker aides) sal later betrek word indien die ondersoek positiewe resultate sou oplewer.

Elektrisiënhelpers word geleer om die verskillende tipes kabels, laste, kontakte, laskasse en gereedskap wat hulle moet gebruik, te identifiseer. Hulle word opgelei in die

\footnotetext{
Versoeke vir afskrifte moet aan skrywer gerig word
} 
konstruksie, installering en herstel van distribusiekasse, kabellaste en instandhouding van die elektriese stelsel ondergronds. Gekwalifiseerde elektrisiënhelpers is ook verantwoordelik vir die herstel van die elektriese gedeeltes van meganiese toerusting soos lokos en wenaste en doen herstelwerk in subkragstasies en aan oorhoofse elektriese kabels in vervoergange ondergronds.

Die doel met die studie was om 'n werkmonstertoets te ontwerp wat kon dien as keuringinstrument vir Swart elektrisiënambagsmanhelpers in die mynbouindustrie. Die redes waarom besluit is op ' $\mathrm{n}$ werkmonstertoets, is soos volg:

- Die voordele van werkmonstertoetse weeg sterker as die nadele, aangesien dit uit die literatuur geblyk het dat werkmonsters die potensiaal as suksesvolle voorspellers het, veral vir beroepe wat psigomotoriese vaardighede vereis.

- Die relatiewe lae peil van geletterdheid van Swart mynwerkers maak werkmonstertoetse meer geskik as papier-en-potloodtoetse. Verder is die toetstake van werkmonsters eenvoudig om te verduidelik.

- $\quad$ Toetsing kon deur Swart mynboupersoneel behartig word aangesien registrasie as sielkundige of psigotegnikus nie noodsaaklik is nie.

\section{NAVORSINGSMETODIEK}

\section{Ontwerp van die werkmonster en beoordelingskaal}

Die tipiese werktaak van elektrisiënhelpers wat as werkmonster aangewend is, was die verbinding van kabels (16mm in deursnee, vier geleiers) in 'n laskas (220 X 110 X 140mm). Hierdie werkmonster, bekend as die kabellastoets, is in samewerking met 'n gekwalifiseerde elektrisiën in bevel van die opleiding van Swart elektrisiënhelpers in 24 onafhanklike taakelemente verdeel (kyk Tabel 1). 'n Totaaltelling vir elke toetsing is verkry deur sommering van die getal items (taakelemente) wat korrek uitgevoer was gedurende elk van die twee toetsings. Aangesien besluit is om van Siegel en Bergman (1975) se leer-en-toets metode met werkmonsters gebruik te maak, is 'n verbeteringtelling verkry deur die telling van die eerste toetsing af te trek van die telling van die tweede toetsing. Hierdie tellings tesame met die normtelling (Dudec) van die Klassifikasietoetsbattery (KTB) 'n algemene basiese keuringtoets om Swart mynwerkers in drie breë beroepskategorieë naamlik toesighouding, 
meganies en arbeiderwerk te plaas - en verwante werkervaring (in maande) het as voorspellers gedien.

'n Beoordelingskaal, bekend as die Werkverrigtingskaal, wat die prestasie van toetslinge bepaal het en as kriterium gedien het, is opgestel. 'n Totaaltelling is bereken deur sommering van die itemwaardes volgens 'n skaal van tellings van 5, 4, 3, 2 en 1, vanaf die mees positiewe tot die mees negatiewe respons. Aangesien die beoordelingskaal uit slegs 12 vrae bestaan het, is besluit om 'n vyfpuntskaal van beantwoording te gebruik ten einde maksimum variansie te probeer verseker.

\section{TABEL 1}

\section{TAAKELEMENTE VAN DIE KABELLASTOETS}

1. Meet kabeleinde teenoor laskas vir ekstra lengte.

2. Merk kabel vir posisie van kabelpasstuk.

3. Maak binder op merk vas.

4. Saag pantsering af sonder om onderlaagmateriaal te beskadig.

5. Verwyder buiteomhulsel.

6. Verwyder pantsering.

7. Pas kabelpasstuk reghoekig.

8. Maak kabeleindpunt aan laskas vas.

9. Gebruik korrekte grootte moersleutels.

10. Vou pantsering terug oor kabel.

11. Maak pantsering aan kabel vas met ten minste drie binders.

12. Verwyder onderlaagmateriaal sonder om geleiers te beskadig.

13. Onderlaagmateriaal moet minstens $12 \mathrm{~mm}$ aan binnekant van laskas verbysteek.

14. Meet beslagringe teenoor geleiers om te bepaal hoeveel isolasie verwyder moet word.

15. Verbind geleiers van dieselfde kleure reguit met mekaar.

16. Beslagringe moet trapsgewys aangebring word.

17. Gebruik korrekte grootte belasringe.

18. Geleiers moet nie aan mekaar of aan die kante van die laskas raak nie.

19. Verwyder isolasie sonder om draadstringe te beskadig.

20. Bring beslagringe aan sodat koperdraadstring vir ongeveer $1 \mathrm{~mm}$ sigbaar is.

21. Krimp een beslagring op korrekte manier.

22. Draai een geleier korrek toe met isolasieband.

23. Druk buite-aarddraad korrek in beslagring. 
24. Buite-aarddraad moet uit minstens sewe draadstringe bestaan.

\section{Die steekproef}

Met die valideringstudie is van die samevallende geldigheidsbenadering of huidige werknemermetode van validering gebruik gemaak. Die steekproef het bestaan uit 53 gekwalifiseerde elektrisiënhelpers. Persone wat opknappingskursusse sou ondergaan, is op die eerste dag getoets om te verseker dat die opknappingskursus as sodanig nie 'n invloed op die toetsresultate sou hê nie. Ander persone is gedurende agtereenvolgende dae, soos prakties geskik was vir die betrokke myn sonder verlies van produktiwiteit, getoets.

Die voorspellingsgeldigheidbenadering of opvolgmetode van validering is gebruik met die kruisvalidering. Die steekproef het bestaan uit 62 nuwelinge wat nog nie as elektrisiënhelpers opgelei was nie. Die huidige beroep van meeste van hulle was werktuigkundearbeiders. Alle toetslinge is op die eerste dag van hulle opleidingskursus getoets om te verseker dat opleiding nie 'n invloed op toetsresultate sou hê nie.

\section{Toepassingsprosedure}

Die Kabellastoets is twee keer op dieselfde groep persone toegepas ten einde 'n studiefase te skep sodat die verbetering in prestasie, indien enige, gemeet kon word. Toetsing het plaasgevind in die opleidingsentrums vir elektrisiënhelpers.

\section{Toetsers en nasieners}

Swart elektrisiënhelperinstrukteurs het opgetree as toetsers, terwyl die nasien van voltooide toetstake deur die Blanke opleidingsbeamptes behartig was.

\section{Aanwysings}

'n Kort inleidende praatjie is deur die toetser aan die toetslinge gegee ten einde hulle te motiveer om hulle beste te lewer en om hulle gerus te stel met die toetssituasie. In die geval van die valideringstudie is geen aanwysings aan die toetslinge gegee nie, aangesien hulle vertroud was met die las van kabels. By die kruisvalideringstudie is 'n volledige stap-vir-stap demonstrasie, tesame met die nodige verbale kommentaar van die manier waarop kabels in 'n laskas verbind word, deur die toetser aan die toetslinge gegee. Toetslinge is toegelaat om vrae te stel wanneer hulle iets nie dadelik begryp het nie. Die demonstrasie is die standaard demonstrasie wat gedurende opleiding gebruik word. 


\section{Eerste toetsing en nasiening}

Die Kabellastoets is deur toetslinge by elke myn onder die toesig van die toetser en 'n aantal instrukteurs gedoen sonder enige verdere hulp of aanwysings. Nadat toetslinge die toets voltooi het, is ' $n$ aantekening van die toetstyd gemaak. Die voltooide werkmonster is hierna deur ' $n$ Blanke opleidingsbeampte nagesien met behulp van 'n kontrolelys bestaande uit die 24 taakelemente. Een myn het van slegs 16 taakelemente gebruik gemaak aangesien kabellaste op 'n ander wyse gedoen word as by myne wat van 24 taakelemente gebruik maak.

\section{Studiefase}

Hierna het die elektrisiënhelperinstrukteurs toetslinge se foute - taakelemente waarop hulle geen punte verdien het nie - individueel aan hulle uitgewys en die korrekte wyse om die betrokke taakelement uit te voer weereens gedemonstreer. Die studiefase het dus gedien as opleiding en aan toetslinge die geleentheid gebied om die korrekte respons aan te leer indien hulle aanvanklik fouteer het. Aan elke persoon is dus dieselfde regverdige kans gebied om sy prestasie te verbeter indien hy wel oor die vaardighede beskik om die werkmonster te bemeester.

\section{Tweede toetsing en nasiening}

Die volgende stap in die ondersoek was om toetslinge die kans te bied om die nuutaangeleerde response van die studiefase prakties toe te pas deur hulle die Kabellastoets 'n tweede keer te laat doen sonder verdere hulp of aanwysings. Die toetstyd is weer aangeteken en dieselfde nasienprosedure as met die eerste toetsing is gevolg.

\section{Werkverrigtingskaal}

Die Werkverrigtingskaal, wat as kriterium gedien het, is deur die Blanke opleidingsbeamptes voltooi deur een antwoord uit vyf moontlike antwoorde op twaalf vrae te merk wat volgens hulle opinie die mees toepaslike beskrywing vir die toetslinge se werkverrigting as gekwalifiseerde elektrisiënhelpers (validering) of leerlingelektrisiënhelpers (kruisvalidering) was. Indien nodig, kon die toetslinge se direkte toesighouer geraadpleeg word. 


\section{Dataontledings}

Alle berekeninge is met behulp van 'n komper uitgevoer en die Statistical Package for the Social Sciences (SPSS) programme (Nie, Hull, Jenkins, Steinbrenner \& Bent, 1975; Hull en Nie, 1979) is gebruik. Alle berekeninge is ten opsigte van die 16-itemtoets gedoen, asook met die 24-itemtoets ten einde te bepaal of die langer toets oor beter diskriminasievermoë sou beskik.

Verskillende beskrywende statistieke soos die rekenkundige gemiddelde en standaardafwyking vir en produkmomentkorrelasies tussen toepaslike veranderlikes is bereken.

Koëffisiënt Alpha is bereken ten einde die betroubaarheid van die werkmonster te bepaal, terwyl geldigheid bepaal is deur middel van korrelasies tussen die voorspellers en die kriterium. 'n Meervoudige stapsgewyse regressieontleding is ook gedoen ten einde 'n voorspellingsmodel van die werkverrigting van elektrisiënhelpers te ontwikkel.

Verdere berekeninge, naamlik ' $n$ itemontleding en faktorontleding van die werkmonster asook 'n variansieontleding om die invloed van werkervaring op prestasie in die werkmonster te bepaal, word volledig gerapporteer in Wolfaardt (1980) en dus nie hier herhaal nie.

\section{BEVINDINGE EN BESPREKING VAN DIE VALIDERING}

\section{Beskrywende statistieke en korrelasies}

Die gemiddelde werkmonstertoetstellings vir die twee toetsings $(12,4$ en 14,6) was hoër as die teoretiese gemiddelde en dui op 'n bogemiddelde prestasie. Die onderskeie standaardafwykings $(1,8$ en 1,6$)$ was klein, wat daarop dui dat die toetslinge nie wyd verspreid was nie en nie genoegsaam tussen toetslinge se prestasie gediskrimineer het nie. Die gemiddelde verbeteringtelling was 2,2 dit wil sê, tydens die tweede toetsing het toetslinge gemiddeld twee items meer korrek beantwoord as tydens die eerste toetsing. Tydens die eerste toetsing het toetslinge gemiddeld 61,2 minute geneem om die toetstaak te voltooi, terwyl die gemiddelde toetstyd vir die tweede toetsing 55,4 minute was. Die gemiddelde tydverskil tussen die twee toetsings was 5,8 minute.

Die gemiddelde telling op die beoordelingskaal, die kriterium $(44,2)$ was hoër as die teoretiese gemiddelde, wat beteken dat die beoordelings oor die algemeen positief was. Die standaardafwyking $(8,6)$ was relatief groot.

'n Betekenisvolle negatiewe korrelasie tussen die eerste toetstelling en die verbeteringtelling $(-0,72)$ is gevind, dit wil sê, oor die algemeen het diegene met die hoogste tellings die 
kleinste verbeteringtellings gehad. Dit is verstaanbaar, aangesien diegene met die laagste aanvanklike telling hulle tellings meer kon verbeter as diegene wat aanvanklik hoë tellings behaal het. 'n Betekenisvolle positiewe korrelasie tussen die tweede toetstelling en die verbeteringtelling $(0,61)$ beteken dat die persone met 'n groot verbetering 'n hoë tweede telling behaal het.

\section{Betroubaarheid, geldigheid en voorspellingsmodel}

Die betroubaarheidkoëffisiënte van die Kabellastoets vir beide toetsings was laag, naamlik 0,32 en 0,57 onderskeidelik. Die interne konsekwentheid van die toets is dus laag en gevolglik psigometries onaanvaarbaar. Die Werkverrigtingskaal blyk 'n betroubare instrument te wees as gevolg van die hoë betroubaarheidkoëffisiënt $(0,94)$.

Geen betekenisvolle korrelasie tussen die voorspellers en die kriterium was gevind nie. Nogtans is gepoog om 'n voorspellingsmodel te ontwikkel deur middel van 'n stapsgewyse regressieontleding. Die eerste toetstelling was die beste voorspeller van die werkverrigting van ambagsmanhelpers, gevolg deur Dudec, werkervaring en die tweede toetstelling. Die meervoudige korrelasies strek vanaf 0,20 tot 0,26 wat beteken dat slegs vier tot sewe persent van die variansie van die kriterium verklaar was. Hierdie syfers is ontoereikend om van enige praktiese waarde vir 'n keuringtoets te wees.

\section{BEVINDINGE EN BESPREKING VAN DIE KRUISVALIDERING}

Wat die werkmonster, die Kabellastoets betref, moet in gedagte gehou word dat die 16item toets dieselfde was as wat tydens die validering gebruik was. Aangesien die myngroep wat betrek was by die kruisvalidering die 24-item toets benut het, word die resultate ten opsigte daarvan ook gerapporteer. Direkte vergelykings tussen die validering en die kruisvalidering word gedoen op grond van die 16-item werkmonster.

\section{Beskrywende statistieke en korrelasies}

Die gemiddelde werkmonstertoetstellings vir die twee toetsings ten opsigte van beide die 16-item toets $(10,7$ en 12,7) en die 24 -item toets $(16,0$ en 19,4) was hoër as die teoretiese gemiddeldes wat dui op 'n bogemiddelde prestasie. Die onderskeie standaardafwykings $(2,6$ en 2,3 asook 3,8 en 3,3) was relatief groot, dit wil sê, tellings was wyd verspreid en die diskriminasie tussen toetslinge se prestasie beter as in die geval van die validering. Die 24- 
item toets diskrimineer die beste tussen goeie en swak presteerders op die werkmonstertoets. Die gemiddelde verbeteringtellings was 2,1 (16-item toets) en 3,3 (24-item toets). Soos met die tweede validering het sommige toetslinge swakker presteer tydens die tweede toetsing na die studiefase. Tydens die eerste toetsing het toetslinge gemiddeld 117 minute aan die toetstaak spandeer en tydens die tweede toetsing 117,5 minute. Hierdie tye is langer as dié wat aangeteken was tydens die validering. Daar moet egter in gedagte gehou word dat die toetslinge hier leerling-elektrisiënhelpers was en nie gekwalifiseerdes soos diegene van die validering nie. Daar was nie 'n betekenisvolle verskil tussen die twee toetstye nie.

Die gemiddelde telling op die Werkverrigtingskaal $(42,2)$ is hoër as die teoretiese gemiddelde, wat beteken dat die beoordeling meesal positief was. Die standaardafwyking $(8,3)$ was relatief groot.

Die volgende betekenisvolle korrelasies ten opsigte van beide die 16- en 24-item toetse is gevind: ' $n$ positiewe korrelasie tussen eerste en tweede toetstellings $(0,49$ en 0,63$)$; negatiewe korrelasie tussen eerste toetstelling en die verbeteringtelling $(-0,59$ en $-0,58)$; ' $n$ positiewe korrelasie tussen die tweede toetstelling en die verbeteringstelling $(0,42$ en 0,28$)$. Dieselfde interpretasies soos voorheen beskryf, kan hieraan geheg word. Ten opsigte van die 16-item toets is 'n betekenisvolle positiewe korrelasie tussen Dudec en die verbeteringtelling $(0,40)$ gevind en dieselfde afleiding soos voorheen beskryf kan gemaak word. Hierdie korrelasie was hoër as dié van die validering.

\section{Betroubaarheid, geldigheid en voorspellingsmodel}

Die betroubaarheidskoëffisiënt van die werkmonstertoets ten opsigte van beide toetsings was 0,64 vir die 16-item toets en 0,75 in die geval van die 24 -item toets. Soos verwag kon word, is die interne konsekwentheid van die langer toets hoër. Die betroubaarheidskoëffisiënt van die werkmonster is dus hoër as wat die geval was met die validering. Die betroubaarheidskoëffisiënt $(0,92)$ van die Werkverrigtingskaal was hoog en die resultaat van die validering word hiermee bevestig.

In teenstelling met die validering is enkele betekenisvolle korrelasies gevind. Vir beide die 16-item en 24-item toetse bestaan daar 'n betekenisvolle positiewe korrelasie van die tweede toetstelling $(0,34$ en 0,30$)$ verbeteringtelling $(0,32$ en 0,26$)$ en Dudec $(0,39)$ met die kriterium. In terme van variansie verklaar is die korrelasies egter laag.

Deur stapsgewyse regressieontleding met die 16-item werkmonster en ander voorspellers, is 'n voorspellingsmodel ontwikkel (kyk Tabel 2). Die tweede toetstelling was die 
beste voorspeller van die werkverrigting van elektrisiënhelpers, gevolg deur Dudec en werkervaring. Die meervoudige korrelasies strek vanaf 0,40 tot 0,52 wat beteken dat 16 tot 27 persent van die variansie verklaar was, wat hoër was as die ooreenstemmende syfers van die validering. Die resultate is gedeeltelik in konflik met die validering, waar die eerste toetstelling en Dudec die twee beste voorspellers was.

Op dieselfde wyse is ook 'n voorspellingsmodel vir die 24-item toets en ander voorspellers ontwikkel (kyk Tabel 3). Die bevinding was dat Dudec die beste voorspeller was, gevolg deur die tweede toetstelling en verbeteringtelling. Die meervoudige korrelasies strek vanaf 0,39 tot 0,55 wat 15 tot 30 persent van die variansie verklaar. Hoewel 'n kruisvalidering met die 24-item toets nie gedoen is nie, kon dieselfde gevolgtrekkings as in die geval van die 16-item toets gemaak word, naamlik dat 'n kombinasie van die tweede toetstelling van die Kabellastoets en Dudec die beste voorspelling van die werkverrigting sal wees.

\section{$\underline{\text { TABEL } 2}$}

\section{VOORSPELLINGSMODEL VAN DIE WERKVERRIGTING VAN ELEKTRISIËNHELPERS (16-ITEM TOETS)}

\begin{tabular}{|l|c|c|c|c|}
\hline & Stap 1 & Stap 2 & Stap 3 & Stap 4 \\
\hline Meervoudige Korrelasie & 0,40 & 0,51 & 0,52 & 0,52 \\
Variansie verklaar & 0,16 & 0,26 & 0,27 & 0,27 \\
Variansie verklaar & 0,15 & 0,24 & 0,22 & 0,21 \\
$\quad$ (aangepas) & & & & \\
Standaardskattingsfout & 7,51 & 7,10 & 7,15 & 7,21 \\
F-verhouding & 10,74 & 9,76 & 6,51 & 4,85 \\
Vryheidsgrade & 1 en 56 & 2 en 55 & 3 en 54 & 4 en 53 \\
Konstant & 23,15 & 21,72 & 22,21 & 23,14 \\
Belading: & & & & \\
$\quad$ Toetstelling, toetsing 2 & 1,43 & 1,20 & 1,21 & 1,12 \\
Dudec & & 1,38 & 1,35 & 1,27 \\
Ervaring & & & $-0,02$ & $-0,02$ \\
Verbeteringtelling. & & & & 0,20 \\
Standaardfout van belading & 0,44 & 0,42 & 0,43 & 0,48 \\
& & 0,50 & 0,51 & 0,55 \\
& & & 0,05 & 0,05 \\
& & & & 0,47 \\
\hline
\end{tabular}




\section{TABEL 3}

\section{VOORSPELLINGSMODEL VAN DIE WERKVERRIGTING VAN ELEKTRISIËNHELPERS (24-ITEM TOETS)}

\begin{tabular}{|l|c|c|c|c|}
\hline & Stap 1 & Stap 2 & Stap 3 & Stap 4 \\
\hline Meervoudige Korrelasie & 0,39 & 0,53 & 0,54 & 0,55 \\
Variansie verklaar & 0,15 & 0,28 & 0,29 & 0,30 \\
Variansie verklaar (aangepas) & 0,14 & 0,26 & 0,25 & 0,25 \\
Standaardskattingsfout & 7,54 & 7,00 & 7,01 & 7,06 \\
F-verhouding & 10,22 & 10,87 & 7,47 & 5,61 \\
Vryheidsgrade & 1 en 56 & 2 en 55 & 3 en 54 & 4 en 53 \\
Konstant & 36,12 & 18,18 & 19,79 & 20,04 \\
Belading: & & & & \\
$\quad$ Dudec & 1,67 & 1,55 & 1,48 & 1,45 \\
Toetstelling, toetsing 2 & & 0,91 & 0,82 & 0,85 \\
Verbeteringtelling & & & 0,29 & 0,26 \\
Ervaring & & & & $-0,03$ \\
Standaardfout van belading & 0,52 & 0,49 & 0,50 & 0,50 \\
& & 0,29 & 0,31 & 0,31 \\
& & & 0,33 & 0,34 \\
& & & & 0,05 \\
\hline
\end{tabular}

Bogenoemde resultate beteken dat die tweede toetstelling op die werkmonstertoets, na 'n studiefase ten einde persone 'n kans te bied om hulle prestasie te verbeter tesame met prestasie op die KTD, moontlik die potensiaal het om die werkverrigting van ambagsmanhelpers te voorspel.

\section{GEVOLGTREKKING}

Die resultate van die kruisvalidering was oor die algemeen gunstiger as dié van die validering, maar steeds onbevredigend uit 'n psigometriese oogpunt aangesien slegs 27 persent van die variansie van die werkverrigtingkriterium verklaar kan word.

Die resultate het daarop gedui dat die 24-item toets beter tussen toetslinge diskrimineer as die 16-item toets, hoewel dit nie in 'n opvolgstudie bevestig kon word nie. Met die kruisvalidering was die gemiddeldes nader aan die teoretiese gemiddeldes as wat met die validering gevind is. Die standaardafwykings was groter wat dui op ' $n$ beter diskriminasie in die prestasie van toetslinge. Die betroubaarheidskoëffisiënte was hoër vir die kruisvalideringgroep en betekenisvolle korrelasies tussen sommige voorspellers en die kriterium is gevind. 'n 
Meer suksesvolle voorspellingsmodel kon gedurende die kruisvalidering ontwikkel word as wat tydens die validering moontlik was: hoër meervoudige korrelasies is behaal wat tot 27 persent van die variansie van die kriterium verklaar het. Hoewel die betroubaarheid van die kriterium hoog was, kon die geldigheid daarvan nie bepaal word nie.

Ter samevatting, indien meer variansie verklaar was, sou die resultate daarop kon dui dat 'n praktiese toets soos die Kabellastoets gekombineer met ' $n$ instrument wat kognitiewe vermoëns meet, die potensiaal het om suksesvolle werkverrigting van ambagsmanhelpers te voorspel. Aangesien min variansie verklaar was, kon kansfaktore 'n rol gespeel het. Die resultate van die huidige ondersoek is nie so gunstig dat die geïdentifiseerde voorspellers van enige praktiese waarde in 'n keuringbattery sou wees nie.

\section{OPSOMMING}

'n Werkmonstertoets, die Kabellastoets, wat kan dien as keuringinstrument vir Swart elektrisiënambagmanhelpers in die mynbouindustrie is ontwerp en toegepas met ' $n$ beoordelingskaal as kriterium. Die voorspellers was tellings op twee toetsings met die werkmonster, 'n verbeteringtelling, Dudec en verwante werkervaring. ' $n$ Valideringstudie $(N=53)$ het lae betroubaarheidskoëffisiënte en geen betekenisvolle korrelasies tussen voorspellers en kriterium opgelewer nie, maar 'n kruisvalidering $(N=62)$ het aangetoon dat 'n kombinasie van die tweede toetstelling en Dudec werkverrigting kan voorspel. Die meervoudige korrelasies $(0,40$ tot 0,52) was egter laag en die variansie wat verklaar word onvoldoende om van enige praktiese waarde in 'n keuringbattery te wees.

\section{VERWYSINGS}

Hull, C.H. \& Nie, N.H. SPSS Update - New procedures and facilities for releases 7 and 8. New York: McGraw-Hill, 1979.

Nie, N.H., Hull, C.H., Jenkins, J.G., Steinbrenner, K. \& Bent, D.H. SPSS-Statistical Package for the Social Sciences (2nd Ed.) New York: McGraw-Hill, 1975.

Siegel, A.I. and Bergman, B.A. A job learning approach to performance prediction. Personnel Psychology, 1975, 28, 325-339.

Wolfaardt, J.B. Die ontwerp en beoordeling van werkmonstertoetse vir Swart ambagsmanhelpers in die mynbouindustrie. Ongepubliseerde D.Phil proefskrif, Universiteit van Pretoria, Pretoria, 1980.

Wolfaardt, J.B. Werkmonsters as keuringtoetse. Aanvaar vir publikasie in Perspektiewe in die Bedryfsielkunde. 1984. 